\title{
Embolization of Arteriovenous Malformations in Floor of Mouth with Ethanol and Coil-Assisted Dominant Outflow Vein Occlusion
}

\section{Lixin Su}

Shanghai Ninth People's Hospital

\section{Deming Wang}

Shanghai Ninth People's Hospital

Lianzhou Zheng

Shanghai Ninth People's Hospital

\section{Xiao Li}

Shanghai Ninth People's Hospital

\section{Xindong Fan}

Shanghai Ninth People's Hospital

Xitao Yang ( $\nabla$ xitao123456@126.com )

Shanghai Ninth People's Hospital

\section{Research Article}

Keywords: arteriovenous malformation, floor of mouth, embolization, ethanol

Posted Date: January 19th, 2022

DOI: https://doi.org/10.21203/rs.3.rs-1246049/v1

License: (9) (i) This work is licensed under a Creative Commons Attribution 4.0 International License. Read Full License 


\section{Abstract \\ Purpose}

To evaluate the outcomes and safety of embolization of the arteriovenous malformations (AVMs) in the floor of the mouth with ethanol combined with coil-assisted dominant outflow vein (DOV) occlusion.

\section{Materials and methods}

Between January 2017 and June 2018, 10 consecutive patients with AVMs in the floor of the mouth and DOVs who underwent ethanol embolization combined with DOV occlusion were enrolled. All patients completed the course of clinical follow-up (range: 14-37 months; mean: 24.8 months). Indications, techniques, complications, and outcomes were reviewed.

\section{Results}

The patients underwent 24 ethanol embolization procedures (range: 1-4; mean, 1.9) with 22 detachable coils and 139 nester coils. 5 patients (50\%) exhibited complete response, and the $5(50 \%)$ exhibited partial response. The minor complications, including mucosal blistering and ulcers, occurred in 3 patients (30\%), but with spontaneous recovery. 3 patients $(30 \%)$ had coil exposure heal with minor debridement. No major complications were observed during the study.

\section{Conclusion}

Ethanol embolization combined with coil-assisted DOV occlusion has the potential to treat the AVMs in floor of mouth with acceptable risk of complications.

\section{Introduction}

The arteriovenous malformations (AVMs) are congenital vascular abnormalities, with the appearance of arteriovenous fistulas as a significant feature. The symptoms can vary widely, depending on the location and severity of the $\operatorname{AVMs}(1,2)$.

The AVMs located in the floor of the mouth are exceedingly rare and characterized by aesthetic or functional problems. symptoms can range from asymptomatic pulsation to a potentially life-threatening hemorrhage and limitation of breathing(3-5). The low morbidity of the AVMs in the floor of the mouth limits comprehensive research to find the standard treatment protocols, and the anatomic location makes the management of such lesions technically challenging. 
The purpose of the present study was to retrospectively assess the technical and clinical safety and effectiveness of ethanol embolization of the high-flow AVMs in the floor of the mouth along with coilassisted dominant outflow vein (DOV) occlusion.

\section{Materials And Methods}

\section{Patients}

This study received approval from the Institutional Review Board of the Shanghai Ninth hospital, and patient informed consent was acquired. Between January 2017 and June 2018, 10 consecutive patients with AVMs located in the floor of the mouth who underwent ethanol embolization in combination with coil-assisted DOV occlusion were enrolled. The AVMs with DOV were defined as multiple arteriolar components of the nidus shunted into dilated venous components and can be identified as a part of a enlarged outflow vein on an angiogram. Cases with extensive anatomy structure involved who's both the floor of the mouth and base of the tongue or the oropharyngeal area affected were not included from this series. The risks and advantages of the operation were discussed in detail with all the patients, and written consent for undergoing the operation was obtained. For participants that are minors (age less than 16 years), informed consent had been obtained from parents. All methods were performed in accordance with the relevant guidelines and regulations.

The study group consisted of 10 patients ( 4 males and 6 females) with a mean age of 32.1 years (range: 13-48 years) during the treatment (Table 1). All the patients exhibited multiple symptoms. The most common symptoms were swelling, pulsation/thrill and hemorrhage (Table 1). The clinicians used the standard staging system described by the Schobinger stage, which was adopted by the International Society for the Study of Vascular Anomalies (ISSVA) for the evaluation of the clinical manifestations of the AVMs(6). 7 patients (70\%) had Schobinger stage II AVMs, and 3 patients $(30 \%)$ had Schobinger stage III AVMs (Table 1). After the clinical investigation, enhanced computed tomography (CT) scan was recommended to evaluate the hemodynamic and anatomic features (Figure 1A, B). The feeding arteries, nidus and drainage veins were defined using superselective digital subtraction angiography (DSA) in all patients before embolization. The clinicians recorded the patients' sex and age, Schobinger stage, lesion location, and clinical manifestations (Table 1). For the patients with acute torrential hemorrhage, the bleeding portion was sutured for hemostasis.

\section{Endovascular techniques}

All the procedures of embolization were performed under general anesthesia via nasal intubation. The oxygen saturation, invasive arterial pressure, electrocardiogram (ECG) and end-tidal carbon dioxide levels were constantly monitored through the procedure.

\section{Occlusion of the DOV}


All the patients underwent selective angiography of the related artery (lingual and facial artery) through femoral approach to determine the detailed angioarchitecture of the AVM (Figure 2A). The DOV was identified as obvious dilated outflow vein according to venous phase of selective angiograms. The tortuous arteriovenous components of the nidus (Figure 2B) and DOV were observed in all angiograms (Figure 2C).

Once the DOV identified, it was occluded in the following manner: a 17.8-G needle (Cook, Bloomington, Indiana) was used to puncture the DOV with the guidance of a roadmap percutaneously or transmucosal. After verify the positioning of the needle in the DOV by venogram (Figure 3A), a 2.2-F microcatheter (Asahi, Seto, Japan) was introduced into the dilated venous sac through the needle (Figure 3B). After confirming the correct positioning of the microcatheter, three-dimensional (3D) detachable coils (EV3, Irvine, California) were inserted through the microcatheter (Figure 3C). The external pressure to the submandibular region can be applied manually with a finger of the operator to the proximal end after the insertion of the detachable coil. This pressure stimulates colis to form a 3-D pattern and reduces the risk of coil migration to some extent. After the satisfactory obliteration of the distal end of the draining veins, Nester coils (Cook, Bloomington, Indiana) were released to make a compact obliteration of the DOV. Because of the size and tortuous of DOV in the floor of the mouth, coils with small size and soft physical properties were preferred. The insertion of the coils was stopped once the venogram showed a significant reduction in the outflow from the vein and contrast stain (Figure 3C). The size, type and number of coils were recorded in all the cases.

\section{Ethanol embolization}

Absolute ethanol was injected into the nidus through the needle or microcatheter. The volume and rate of ethanol per injection were determined by several venograms from the needle or from the microcatheter before absolute ethanol injected into the nidus. The contrast material should be noted only in the nidus and drainage veins, but not in the feeding arteries. Angiography of the feeding artery was carried out 3-5 minutes after ethanol injection to determine whether the nidus of the AVM was embolized. Repeated ethanol injection was required if the nidus was still noted.

\section{Postoperative management}

The management after ethanol embolization included intravenous (IV) infusion of a tapering dose of IV methylprednisolone was administered after ethanol embolization for 3-5 days to relieve the swelling. Ranitidine was given to protect against gastric or duodenal ulcer development. The patients were routinely monitored in the intensive care unit (ICU) overnight with nasal intubation to avoid unexpected severe swelling. The nasal intubation was removed in 1-3 days according to the degree of swelling relief.

\section{Evaluation of the clinical data and follow-up results}


Follow-up was performed at 1-3-month intervals after the initial treatment. enhanced CT or angiography was recommended when the symptoms and signs of the patients worsened. Additional embolotherapy was required if the AVMs were still observed or clinical symptom remained. For the patients with a complete response to the treatments, a telephone questionnaire at 3-month intervals and physical examination at 1 -year intervals were suggested.

The following 4-point grading scale was used to evaluate the clinical symptoms and signs (10): (i) adverse response, AVM became larger or pain was aggravated; (ii) no response, AVM was $\leq 49 \%$ resolved; (iii) partial response, AVM was 50-99\% resolved; and (iv) complete response, AVM was 100\% resolved. Complete response was defined as the complete resolution of the clinical signs or $100 \%$ devascularization on arteriography after more than 12 months of follow-up (Figure 3D). Partial response was defined as the complete resolution or improvement of the clinical symptoms and signs with 50-99\% devascularization of the AVMs. No response was defined as no improvement in the clinical signs with $\leq 49 \%$ devascularization. Adverse response was defined as an aggravation of the clinical signs regardless of the degree of devascularization on arteriography. The partial and complete responses were considered as effective therapeutic outcomes.

The complications related to the embolization procedure were classified as minor or major(7). The minor complications included any temporary adverse sequelae, such as transient nerve injury or spontaneous mucosal necrosis and coil exposure heal with minor debridement. The major complications included permanent adverse sequelae, death, and the need for major therapy. The transient pain and swelling of the treated area after the embolization were not judged to be complications.

\section{Results}

14 coil-assisted DOV occlusions were performed. In total, 22 3D detachable coils (0.018-inch, EV3, Irvine, California) and 139 3D Nester coils (0.018-inch, Cook, Bloomington, Indiana) were used to occlude the DOV (Table 2). In all patients, no complications related to DOV occlusion with coils occurred. During the 24 ethanol embolization procedures (range: 1-4; mean: 2.4) in 10 patients, the amount of ethanol ranged from 2.5 to $18.0 \mathrm{ml}$. All 10 patients $(100 \%)$ in all 24 procedures exhibited focal swelling in the floor of the mouth that resolved within 2 weeks. According to the angiographic findings, the AVMs achieved $100 \%$ devascularization in 5 patients (50\%), 50-99\% devascularization in 5 patients (50\%). Clinical symptoms and signs in all patients showed resolved. The ethanol embolization of the AVMs in floor of mouth with coil-assisted DOV occlusion achieved an effective therapeutic outcome in all 10 patients (Table 2).

\section{Complications}

During the study, no major complications were observed. Al 10 patients (100\%) exhibited focal swelling over the lesions immediately after the treatment, which was significantly relieved in 3 days. 3 patients (30\%) experienced blister and mucosal ulcer over the AVM lesions that healed spontaneously in 1-3 
weeks with no remaining tissue defect. 3 patients (30\%) had coil exposure heal with minor debridement (Figure 4). No procedure-related mortalities or major complications were recorded.

\section{Discussion}

The floor of the mouth is a horizontally aligned U-shaped space situated in the part of the oral cavity that lies beneath the tongue mainly combined with the sublingual space and submandibular space, which is separated by the mylohyoid muscle. Within the floor of the mouth are the sublingual gland, submandibular gland, portions of the muscles of the tongue, lingual nerves, etc.(8). Because of its location, the AVMs in this region can result in an enormous variety of symptoms, such as swelling, difficulty in breathing and bleeding. The factors such as trauma, hormonal changes, spontaneous internal bleeding, and prior interventions have also been associated with sudden progression and subsequent recognition of the disease $(3,9,10)$. The treatment of the AVMs in the floor of the mouth is challenging, and relevant reports are limited.

Few case reports have described various treatment methods of the AVMs in the floor of the mouth including surgical resection, embolization, or combined procedure $(3-5,10)$. Ligation of the feeding arteries is not recommended because the AVM regrows rapidly by recruiting multiple small feeders from the surrounding vascular territories. After the development of the complex feeding vessels, effective embolization or surgery is very difficult. Surgical resection without preoperative embolization should be avoided because of the risk of massive bleeding. Preoperative superselective transarterial embolization can make the procedure of resection more controllable(11-13).

The recent advancements in interventional radiology have enhanced the efficacy of endovascular embolization in controlling immediate bleeding control, thereby preserving the functional anatomy and morphology. In the Zheng report, a group of 52 patients with lingual AVMs was treated by ethanol embolization, and effective therapeutic outcomes were achieved in $96 \%$ of patients(14). Anatomically adjacent, the AVMs in the floor of the mouth and lingual area share some common symptoms, as they both are the components of the upper respiratory tract. Unlike local lingual AVMs, the AVMs in the floor of the mouth are more difficult to resect because of their complex surrounding anatomical structure. The main goal of AVM therapy in this region is often maximal control of shunting and palliation of the clinical manifestations. A cure is possible in some of the favorable angiographic types and arteriovenous fistulas. In the diffuse AVMs, the objective is to prevent the outcome of the treatment from being worse than the disease $(1,15-17)$.

The main goal of AVM therapy is the maximal disruption of the abnormal communication between the arteries and veins. Although many agents, such as N-butyl cyanoacrylate (NBCA) and Onyx, have been introduced for embolization of the mandibular or maxilla AVMs, they do not destroy the endothelial cells of the AVMs(18-20). Furthermore, the chronic hypoxic and inflammatory states caused by incomplete embolization have been shown to cause re-endothelialization and recanalization of the AVM. However, the introduction of absolute ethanol results in denudation of the endothelial cells from the vascular wall, 
thereby causing fractures in the vascular wall to the level of the internal elastic lamina. These changes account for the curative effects and permanence of embolization(17, 21, 22). Notably, even embolization using absolute ethanol, which is the most powerful embolization agent, cannot provide satisfactory results for all extracranial AVMs in the head and neck. In fact, in the AVMs with obvious DOV, the injected ethanol may sweep away from the nidus before it causes nidus occlusion; thus, decreasing the effectiveness of the treatment and increasing the potential risk of complications related to embolic agent migration, such as adjacent tissue damage and cardiopulmonary dysfunction. Therefore, coils are necessary to occlude the DOV and decrease the flow of the nidus before ethanol injection(23-25). Hence, making it possible to treat the AVMs with fewer embolization sessions and a lower amount of ethanol in a single procedure. As indicated during the treatment of the AVMs with DOV in the floor of the mouth, the use of absolute ethanol and coils is recommended as the primary agents for embolization. Briefly, We benefit from DOV embolization with follow several points: 1. DOV embolization slowed down the blood flow which makes the nidus clearer to be identified. 2. DOV embolization slowed down the blood flow which makes it easily to destroyed with limited amount of absolute ethanol. 3. In the long run, DOV embolization may possibility reduce the recurrence rate of arteriovenous malformations.

Absolute ethanol is more likely to cause swelling than other embolic agents. When treating oropharyngeal vascular malformations, severe and unpredictable swelling will lead to asphyxia. When compared with the lingual AVMs, the effect of the AVMs in the floor of the mouth on the respiratory tract is weaker. Therefore, preventive tracheotomy is often not necessary. Considering that the degree of swelling after absolute ethanol injection is not only related to the size of the lesion but also the flow rate of the lesion and the local retention of absolute ethanol, it is necessary to retain endotracheal intubation for 1-3 days after the operation. The swelling caused by absolute ethanol often reaches a peak in $48-72$ hours, and then gradually alleviates in 1-2 weeks. Corticosteroids can effectively accelerate the relief of swelling, but gastric mucosal protectants should be given to prevent gastric ulcers. Mucosal blister, superficial local mucosa necrosis and coil exposure are common complications after embolization of the AVMs in the floor of the mouth and are especially observed in patients who exhibit bleeding before embolization. Debridement needs to be carried out to remove the exposed coils with limited bleeding. It should be noted that the excessively remove the coils was unnecessarily

This study has several limitations. Firstly, this study presents a retrospective report that includes a limited number of case series. A prospective study is needed for more precise assessment. Secondly, very complicated cases of both the floor of the mouth and base of the tongue or the oropharyngeal area involved were not included in this series, which is a major challenge for surgeons and radiologists.

\section{Conclusion}

In conclusion, the treatment of the AVMs in the floor of the mouth is one of the most challenging clinical issues. Ethanol embolization is safe and efficacious for treating specific cases when it is performed with appropriate technique and caution. Staged and precise ethanol embolization is likely to be safe and clinically effective. Additionally, the proper use of coils to occlude the DOV is also necessary. 


\section{Declarations}

\section{Acknowledgments:}

The authors thank Prof. Wayne F. Yakes for teaching the technique of ethanol embolization and supporting clinical work these years. This study was supported by the Health Clinical Research Project of Shanghai Municipal Health Commission [No. 202140425]; The Clinical Research Program of Ninth People's Hospital, Shanghai Jiaotong University, School of Medicine [No. LYLJ201911]

\section{Author contributions:}

Conception and design: LX Su, XT Yang

Analysis and interpretation: LX Su, X Li, XD Fan, XT Yang

Data collection: LX Su, DM Wang, LZ Zheng, X Li, XD Fan, XT Yang

Writing the article: LX Su, DM Wang, XT Yang

Critical revision of the article: LX Su, DM Wang

Overall responsibility: XT Yang

Final approval of the article: All authors

\section{Competing interests[}

The author(s) declare no competing interests.

\section{Data availability statement!}

The datasets generated during and/or analysed during the current study are available from the corresponding author on reasonable request

\section{References}

1. Alsuwailem A, Myer CMt, Chaudry G. Vascular anomalies of the head and neck. Seminars in pediatric surgery. 2020;29(5):150968.

2. Brahmbhatt AN, Skalski KA, Bhatt AA. Vascular lesions of the head and neck: an update on classification and imaging review. Insights into imaging. 2020;11(1):19.

3. Chimona TS, Papadakis CE, Hatzidakis AA, Velegrakis GA. Arteriovenous malformation of the floor of the mouth: a case report. European archives of oto-rhino-laryngology: official journal of the European Federation of Oto-Rhino-Laryngological Societies (EUFOS) : affiliated with the German Society for Oto-Rhino-Laryngology - Head and Neck Surgery. 2005;262(11):939-42. 
4. Gharaibeh TM, Safadi RA, Rawashdeh MA, Hammad HM. Plunging arteriovenous malformation in the floor of the mouth: a case report. Br J Oral Maxillofac Surg. 2010;48(8):e35-7.

5. Taskin U, Yigit O, Bilici S, Kocer N. Giant arteriovenous malformation of the floor of the mouth presenting with dysarthria and difficulty in swallowing. The Journal of craniofacial surgery. 2012;23(2):e86-8.

6. Ahlawat S, Fayad LM, Durand DJ, Puttgen K, Tekes A. International Society for the Study of Vascular Anomalies Classification of Soft Tissue Vascular Anomalies: Survey-Based Assessment of Musculoskeletal Radiologists' Use in Clinical Practice. Current problems in diagnostic radiology. 2019;48(1):10-6.

7. Angle JF, Siddiqi NH, Wallace MJ, Kundu S, Stokes L, Wojak JC, et al. Quality improvement guidelines for percutaneous transcatheter embolization: Society of Interventional Radiology Standards of Practice Committee. J Vasc Interv Radiol. 2010;21(10):1479-86.

8. Laine FJ, Smoker WR. Oral cavity: anatomy and pathology. Semin Ultrasound CT MR. 1995;16(6):527-45.

9. Fujita M, Yamamoto Y, Sasaki S, Oyama A, Funayama E, Furukawa H. Transarterial Embolization and Transmucosal Sclerotherapy That Led to Successful Deliveries in a Patient With Symptomatic Arteriovenous Malformation of the Tongue. The Journal of craniofacial surgery. 2017;28(7):e675-e8.

10. Bailey BM, Thomas AA. An arterio-venous fistula of the floor of mouth and tongue. $\mathrm{Br} \mathrm{J}$ Oral Maxillofac Surg. 1984;22(6):431-8.

11. Coldwell DM, Stokes KR, Yakes WF. Embolotherapy: agents, clinical applications, and techniques. Radiographics: a review publication of the Radiological Society of North America, Inc. 1994;14(3):623-43; quiz 45-6.

12. Yakes WF. [Endovascular management of high-flow arteriovenous malformations]. Zhonghua Kou Qiang Yi Xue Za Zhi. 2008;43(6):327-32.

13. Yakes WF. Use of Multiple Sclerosant Agents in Vascular Malformation Management: A World in Endovascular Confusion and Chaos. J Vasc Interv Radiol. 2015;26(10):1494-6.

14. Zheng L, Su L, Wang D, Wang Z, Wen M, Yang X, et al. Ethanol embolization of lingual arteriovenous malformations: Positive experience in 52 patients during 11 years. J Vasc Surg. 2020;72(2):651-7.e4.

15. Griauzde J, Wilseck ZM, Chaudhary N, Pandey AS, Vercler CJ, Kasten SJ, et al. Endovascular Treatment of Arteriovenous Malformations of the Head and Neck: Focus on the Yakes Classification and Outcomes. J Vasc Interv Radiol. 2020;31(11):1810-6.

16. Mayer C, Hattingen E, Schild H, Bootz F, Schröck A. [Interventional radiology in the head and neck region]. Hno. 2017;65(6):482-9.

17. Pekkola J, Lappalainen K, Vuola P, Klockars T, Salminen P, Pitkäranta A. Head and neck arteriovenous malformations: results of ethanol sclerotherapy. AJNR Am J Neuroradiol. 2013;34(1):198-204.

18. Kacker A, Heier L, Jones J. Large intraosseous arteriovenous malformation of the maxilla - a case report with review of literature. Int J Pediatr Otorhinolaryngol. 2000;52(1):89-92. 
19. Limbucci N, Spinelli G, Nappini S, Renieri L, Consoli A, Rosi A, et al. Curative Transvenous Onyx Embolization of a Maxillary Arteriovenous Malformation in a Child: Report of a New Technique. The Journal of craniofacial surgery. 2016;27(2):e217-9.

20. Park ES, Jung YJ, Yun JH, Ahn JS, Lee DH. Intraosseous arteriovenous malformation of the sphenoid bone presenting with orbital symptoms mimicking cavernous sinus dural arteriovenous fistula: a case report. Journal of cerebrovascular and endovascular neurosurgery. 2013;15(3):251-4.

21. Do YS, Yakes WF, Shin SW, Lee BB, Kim DI, Liu WC, et al. Ethanol embolization of arteriovenous malformations: interim results. Radiology. 2005;235(2):674-82.

22. Yakes WF, Krauth L, Ecklund J, Swengle R, Dreisbach JN, Seibert CE, et al. Ethanol endovascular management of brain arteriovenous malformations: initial results. Neurosurgery. 1997;40(6):114552; discussion 52-4.

23. Cho SK, Do YS, Kim DI, Kim YW, Shin SW, Park KB, et al. Peripheral arteriovenous malformations with a dominant outflow vein: results of ethanol embolization. Korean journal of radiology. 2008;9(3):258-67.

24. Li X, Su L, Yang X, Han Y, Wang D, Zheng L, et al. Embolotherapy for High-Flow Arteriovenous Malformations in the Hands Using Absolute Ethanol with Coil-Assisted Dominant Outflow Vein Occlusion. J Vasc Interv Radiol. 2019;30(6):813-21.

25. van der Linden E, van Baalen JM, Pattynama PM. Retrograde transvenous ethanol embolization of high-flow peripheral arteriovenous malformations. Cardiovascular and interventional radiology. 2012;35(4):820-5.

\section{Tables}


Table 1

Baseline features of patients with arteriovenous malformations in the floor of mouth

\begin{tabular}{|lllll|}
\hline Patient No. & Age (yrs)/sex & Schobinger stage & Location involved & Clinical manifestations \\
\hline 1 & $37 / \mathrm{M}$ & II & UL, SM & S/P \\
\hline 2 & $48 / \mathrm{M}$ & II & UL, SL, SM & S/H \\
\hline 3 & $33 / \mathrm{F}$ & III & UL, SM & S/P \\
\hline 4 & I3/F & II & BL, SL, SM & S/P \\
\hline 5 & $28 /$ F & II & UL, SL & S/P/H \\
\hline 6 & 23/ M & II & UL, SL, SM & S/H \\
\hline 7 & II & UL, SM & S/P \\
\hline 8 & $44 / \mathrm{M}$ & II & BL, SL, SM & S/P \\
\hline 9 & $27 / F$ & III & UL, SL, SM & S/PH \\
\hline 10 & III & & \\
\hline Sex: M, male; F, female & & & \\
\hline Location involved: SL, sublingual region; SM, submandibular region, UL, unilateral; BL, biliteral & \\
\hline Clinical manifestations: S, swelling, P, pulsation/thrill, and H, haemorrhage
\end{tabular}


Table 2

Result of ethanol embolization and coil occlusion of dominant outflow veins in arteriovenous malformation in the floor of mouth

\begin{tabular}{|c|c|c|c|c|c|c|}
\hline \multirow{2}{*}{$\begin{array}{l}\text { Patient } \\
\text { No. }\end{array}$} & \multirow{2}{*}{$\begin{array}{l}\text { Number of } \\
\text { Embolization } \\
\text { Procedures }\end{array}$} & \multicolumn{2}{|c|}{ Total number of coils } & \multirow{2}{*}{$\begin{array}{l}\text { Volume of } \\
\text { ethanol } \\
(\mathrm{mL})\end{array}$} & \multirow{2}{*}{$\begin{array}{l}\text { Clinical } \\
\text { follow-up } \\
\text { (mo) }\end{array}$} & \multirow{2}{*}{$\begin{array}{l}\text { Clinical } \\
\text { outcome }\end{array}$} \\
\hline & & $\begin{array}{l}\text { Detachable } \\
\text { coils }\end{array}$ & $\begin{array}{l}\text { Undetachable } \\
\text { coils }\end{array}$ & & & \\
\hline 1 & 3 & 2 & 20 & $15 / 15 / 5$ & 26 & PR \\
\hline 2 & 1 & 1 & 12 & 3 & 25 & CR \\
\hline 3 & 4 & 6 & 28 & $12 / 6 / 16 / 6$ & 22 & CR \\
\hline 4 & 2 & 3 & 16 & $8 / 5$ & 29 & PR \\
\hline 5 & 2 & 1 & 7 & $8 / 4$ & 18 & PR \\
\hline 6 & 3 & 2 & 17 & $18 / 5 / 5$ & 25 & $\mathrm{CR}$ \\
\hline 7 & 1 & 1 & 3 & 9 & 14 & $\mathrm{CR}$ \\
\hline 8 & 3 & 1 & 6 & $12 / 6 / 6$ & 16 & $\mathrm{CR}$ \\
\hline 9 & 3 & 4 & 22 & $11 / 8 / 12$ & 36 & PR \\
\hline 10 & 2 & 1 & 8 & $8 / 6$ & 37 & PR \\
\hline
\end{tabular}

\section{Figures}




\section{Figure 1:}

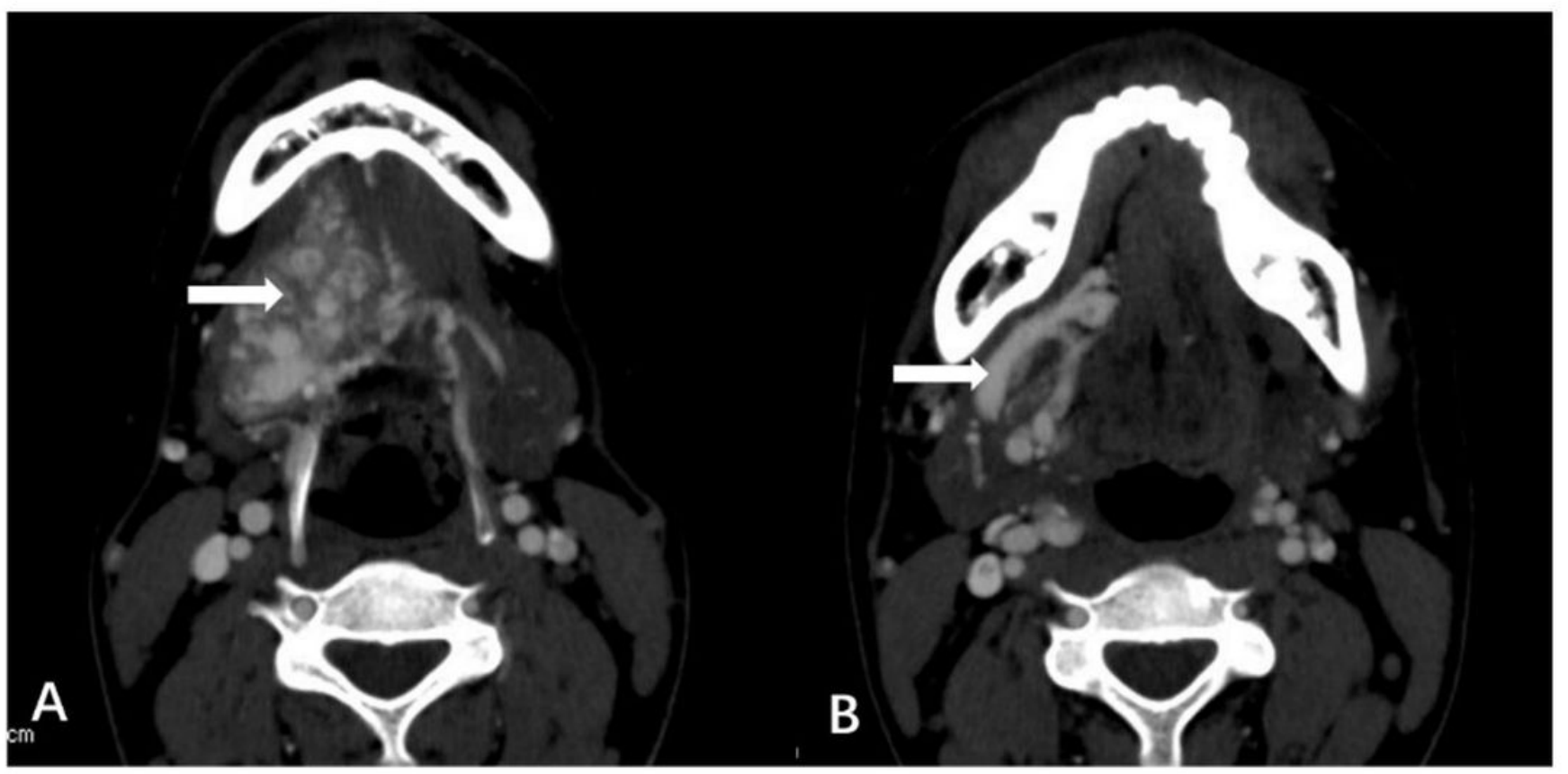

Figure 1

Contrast-enhanced computed tomography (CECT) image shows (A) enhancement nidus of the AVM centered in the floor of the mouth and (B) dilated dominant outflow vein (DOV).

\section{Figure 2}

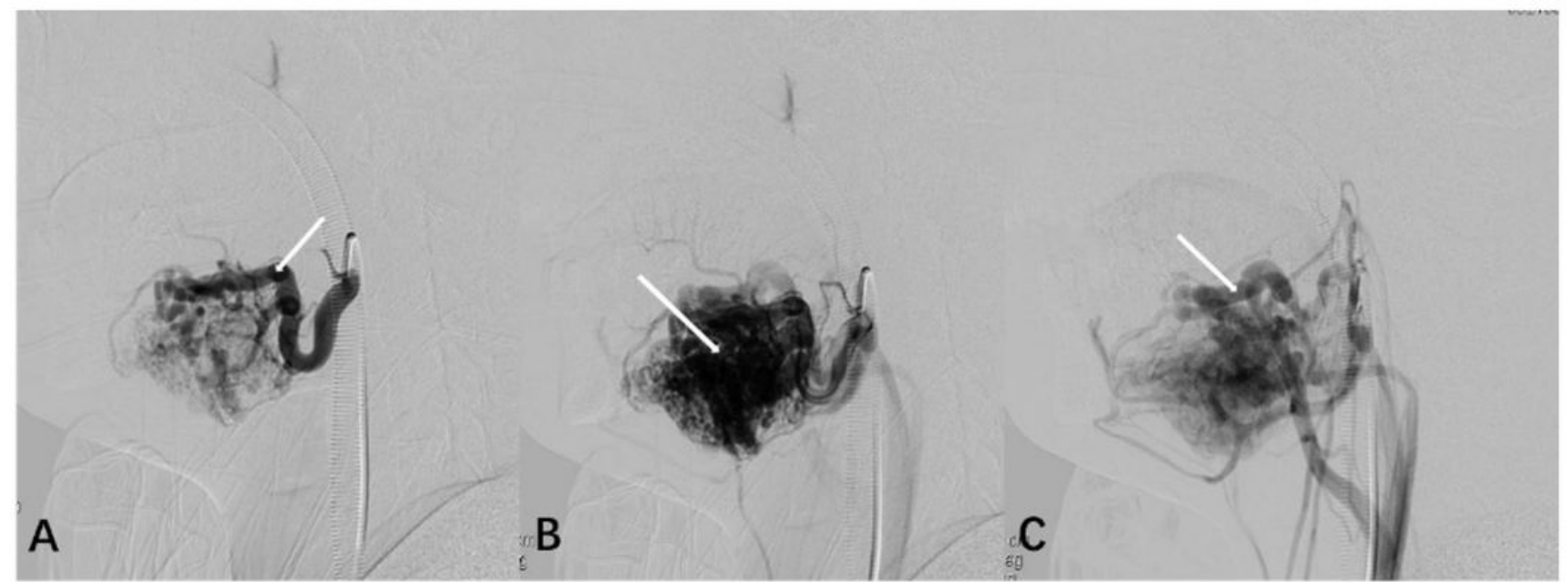

Figure 2 
Angiography of the lingual artery shows (A) dilated feeding artery (arrow) in the arterial phase; (B) nidus (arrow) in the late arterial phase and (C) dilated dominant outflow vein (DOV) (arrow) in the venous phase.

\section{Figure 3:}

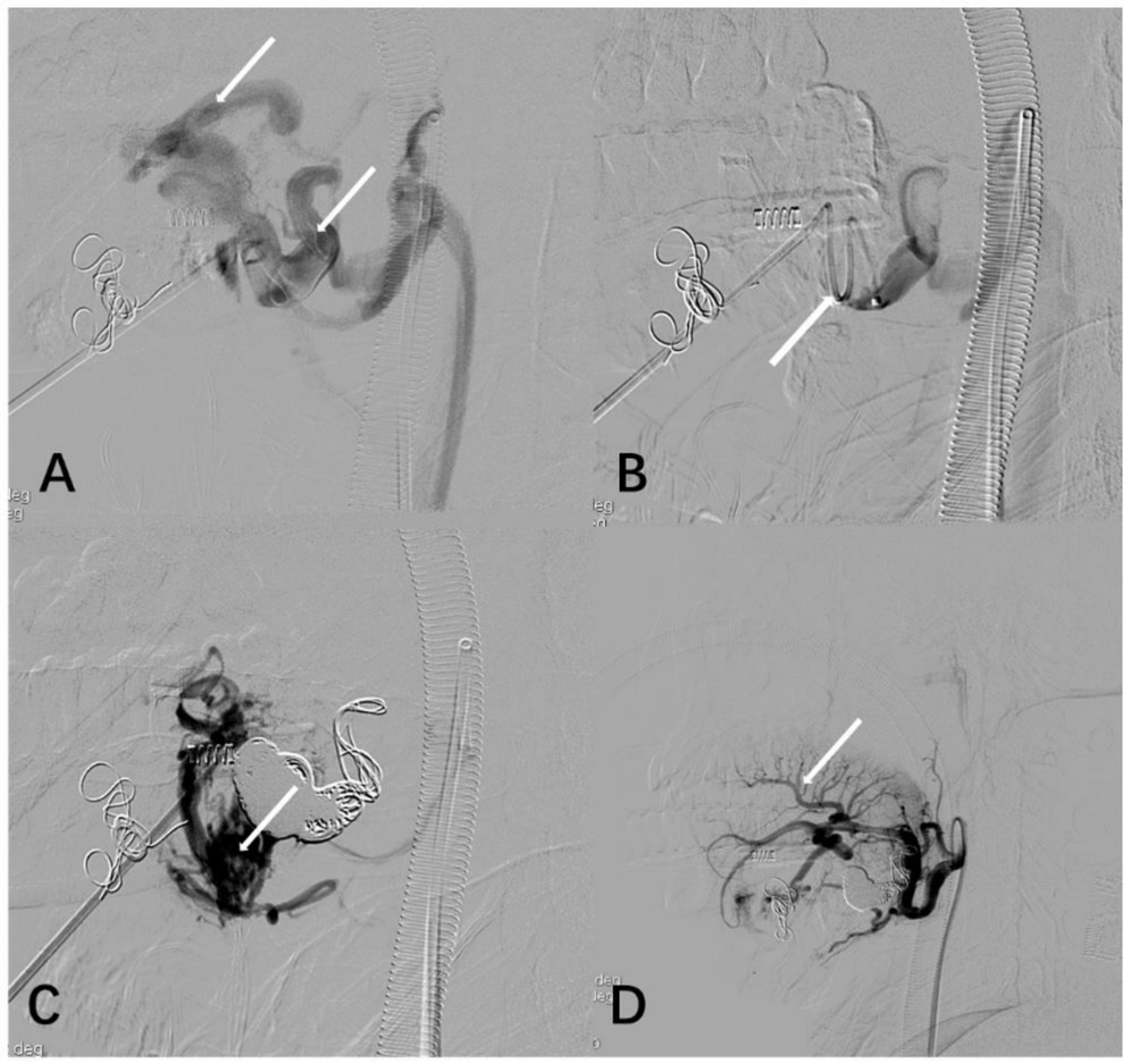

\section{Figure 3}

(A)DOV venogram from direct puncture showing the degree of dilation and direction of reflux vein (arrows); (B) 2.2-F microcatheter (arrow) was introduced into the DOV through the needle. (C) The venogram shows an obvious reduction in an outflow from the vein and contrast stain. (D) Lateral 
angiography of the lingual artery performed after ethanol embolization shows complete obliteration of the AVM and improved blood supply of the tongue (arrow).

\section{Figure 4:}

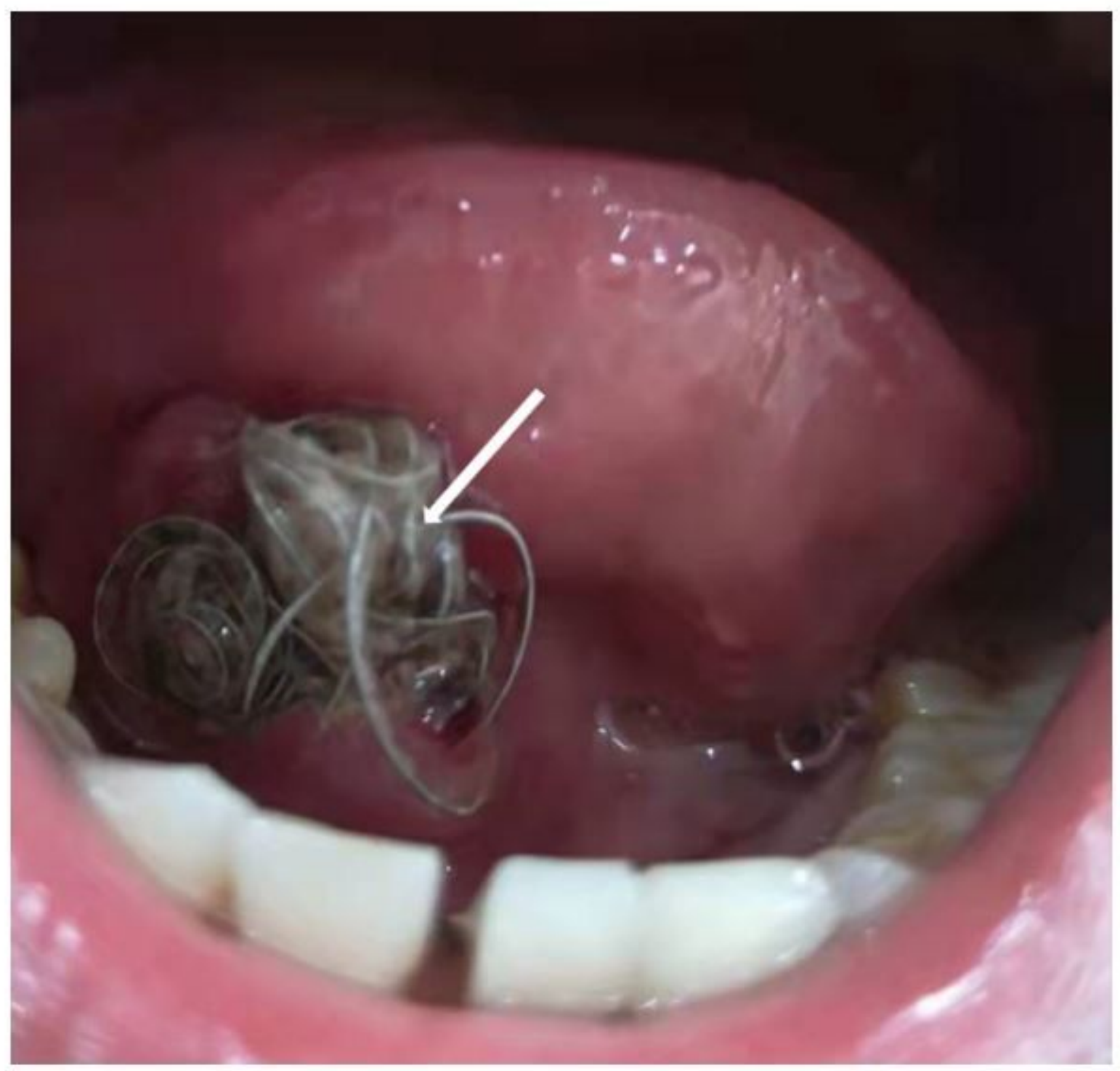

\section{Figure 4}

Local mucosa necrosis and coil exposure after ethanol embolization. 